\title{
AOR
}

Selected Papers of \#AolR2020:

The 22nd Annual Conference of the

Association of Internet Researchers

Virtual Event / 13-16 Oct 2021

\section{NOT FAR ENOUGH: HOW WORKPLACE HARASSMENT POLICIES FAIL TO PROTECT SCHOLARS FROM ONLINE ABUSE}

\author{
Chandell Gosse \\ Royal Roads University \\ Jaigris Hodson \\ Royal Roads University \\ George Veletsianos \\ Royal Roads University
}

\section{Introduction}

Over the last decade, online spaces and digital tools have become a central part of scholarly work and research mobilization (Carrigan, 2016). Email and learning management systems have been deeply embedded in academic labor for some time, with other tools like Twitter and now Zoom becoming everyday addons used to complete and promote scholarly work (Stewart, 2016). However, the integration and reliance on these technologies into scholars' work lives have heightened their online visibility, which has opened the door to new experiences of online abuse, such as Zoom-bombing, doxing, and inappropriate and violent comments (Burnett, 2020; Elmer, Glyn Burton, \& Neville, 2020; Frangou, 2019). Scholars have pointed to the detrimental effect online abuse has on their work, noting that it negatively impacts their research, teaching, and their personal and professional relationships (Authors, 2021a). Scholars also report being left to deal with the consequences of online abuse primarily on their own, with little support from their institution (Authors, 2018b).

\section{Objective}

Given the importance of online spaces/tools in scholars' lives and the detrimental impacts of harassment noted above, colleges and universities must recognize the risks associated with online visibility and have policies in place that address those risks. In this paper, we analyze 41 workplace policies that deal with harassment and discrimination from Canadian Universities and Colleges to understand what these institutions propose to do about online abuse. How institutions propose to protect and support scholars from online abuse provides insight into how they conceive of the issue: namely, it reveals what they Suggested Citation (APA): Gosse, C., Hodson, J.,Veletsianos, G., (2021, October). Not Far Enough: How Workplace Harassment Policies Fail to Protect Scholars From Online Abuse. Paper presented at AolR 2021: The 22nd Annual Conference of the Association of Internet Researchers. Virtual Event: AolR.

Retrieved from http://spir.aoir.org. 
think is problematic and needs to change (Bacchi, 2012). As such, this paper asks: Do university and college harassment policies address online abuse? If so, in what context is online abuse discussed? And how well-positioned are these policies at supporting or protecting scholars from online abuse? To answer these questions, we use Bacchi's (2012) 'What's the problem represented to be?' (WPR) approach. This approach encourages examination of the assumptions and conceptual logics within the framing of a problem to understand implicit problem representations.

\section{Methodology}

We searched the public websites of 232 universities and colleges across Canada for workplace harassment policies and identified policies at $129(56 \%)$ institutions. Using a text search for the terms "online, virtual, cyber, e-/email, social, media, electronic, and digital," we found that only $41(32 \%)$ of the 129 institutions acknowledged online abuse in their policies. Using Nvivo 12 we coded the 41 policies' purpose, scope, procedures, and all mentions of online abuse to identify how university and college community members might be protected from online abuse within the context of their institution's policy. Overall, we found that the policies did not align with what scholars who have experienced online abuse report needing to feel supported by their institutions (Authors, 2018a; 2018b).

\section{Preliminary Findings}

Early analysis identified two problems common across the 41 policies that limit their ability to offer protection and/or support in many cases of online abuse: the first limitation focuses on who the policies apply to, and the second on where the policies apply.

First limitation: To whom the policies apply

The main objective of all policies is to protect members of the university community from harassment from other members of the same institution. While this stipulation is reasonable in the context of a college or university, it precludes perpetrators of online abuse and harassment that are unknown, anonymous, or unrelated to the institutional community. This focus poses serious problems because the online abuse and harassment that academics receive often involve people outside of or unknown to the university community (Burnett, 2020).

\section{Second limitation: Where the policies apply}

Policies often define their scope in relation to university spaces. In the policies we examined, the ones that define their scope in relation to place typically limit abuse to places such as sanctioned university events, events related to work and study, or any other place needed to fulfill duties to the institution. This provision ignores the fact that scholars' online abuse and harassment is not always formally tied to institutional places (Authors, 2021a). Examples include harassment arising from media appearances or receiving abusive and harassing messages on scholars' social media accounts. 


\section{Discussion}

Defining harassment policies in terms of university personnel or spaces excludes acts of online abuse that occur outside of institutionally sanctioned platforms (e.g., social media), outside formally recognized academic labor (e.g., appearing on podcasts, TV, or radio), and by individuals who are not members of the institutions' community. These limitations mean that scholars are left unprotected by their institutions when they experience online abuse.

The need to have institutions step in and offer support and protection against online abuse grows more complex and dire when placed into the current professional and sociopolitical climate. For example, institutions place increasing emphasis on engaging with broader audiences and mobilizing one's work beyond the academy (Barlow \& Awan, 2016). Increasingly, this work is tied to hiring and funding decisions, and social media, op-eds, blogs, and podcasts are effective ways to do this work. The emphasis on engaging with broader and more diverse audiences comes at a time when there are coordinated efforts to undermine and "expose" liberal agendas on university campuses, effectively disciplining, surveilling, and silencing researchers online (Massanari, 2018).

The professional and socio-political conditions, in combination with the personal adverse effects online abuse has on scholars' work, health, and well-being require investment in policies that reflect a changing digital landscape. This may involve a focus on process or procedure over policy conditions, and thus provide flexibility for the kinds of abuse and harassment scholars experience in an increasingly digital professional and social environment.

\section{Future work}

This project is in the early stage of analysis. The next stages include a deeper analysis of the policies as well as interviews with university administrators (e.g., Deans and Vice President Academics/Research) to understand how their institution is prepared to respond to the rising threat of online abuse. Together, these two projects will result in concrete steps to better strengthen institutional responses and provide support and protection that align with the realities of academic labor and online spaces.

\section{References}

Authors (2021a).

Authors (2021b).

Authors (2018a).

Authors (2018b).

Bacchi, C. (2012). Introducing the 'what's the problem represented to be?' approach. In A. Bletas \& C. Beasley (Eds.) Engaging with Bacchi. Adelaide: University of Adelaide Press. 
Barlow, C., and Awan, I. (2016) 'You need to be sorted out with a knife': The attempted online silencing of women and people of Muslim faith within academia. Social Media + Society, 2(4), 1-11. http://doi.org/10.1177/2056305116678896

Burnett, L.D. (2020, October). Right-wing trolls attacked me. My administration buckled. The Chronicle of Higher Education. https://www.chronicle.com/article/right-wing-trollsattacked-me-my-administration-buckled

Carrigan, M. (2016). Social Media for Academics. London: SAGE

Elmer, G., Glyn Burton, A., Neville, S. (2020, June). Zoom-bombings disrupt online events with racist and misogynist attacks. The Conversation.

https://theconversation.com/zoom-bombings-disrupt-online-events-with-racist-andmisogynist-attacks-138389

Frangou, C. (2019, October). The growing problem of online harassment in academe. University Affairs. https://www.universityaffairs.ca/features/feature-article/the-growingproblem-of-online-harassment-in-academe/

Massanari, Adrienne L. (2018). Rethinking research ethics, power, and the risk of vulnerability in the era of the "alt-right" gaze. Social Media + Society, 4(2), 1-9. DOI: $10.1177 / 2056305118768302$

Stewart, Bonnie. (2016). Collapsed publics: Orality, literacy, and vulnerability in academic Twitter. Journal of Applied Social Theory, 1(1), 61-86. 